\title{
Patterns of Niche Partitioning and Alternative Reproductive Strategies in an East African Dung Beetle Assemblage
}

\author{
Andrew Chao • Rebecca Simon-Freeman • Greg Grether
}

Revised: 14 October 2012 / Accepted: 19 October 2012 /

Published online: 28 November 2012

(C) Springer Science+Business Media New York 2012

\begin{abstract}
Sympatric species of coprophagus dung beetles rely on essentially the same resource for provisioning broods, which raises the question of how local species diversity is maintained. Interspecific competition may be mitigated to some extent by large-scale spatial (e.g., habitat type) and temporal (e.g., seasonal) variation in activity. Niche partitioning also occurs at the scale of individual dung pads. We examined the extent to which inter- and intraspecific variation in adult morphology and behavior contribute to spatial and temporal partitioning above and below the dung pad in the dung beetle community of Kibale Forest, Uganda. Excavations in the vicinity of dung pads revealed significant heterogeneity among species and guilds in the lateral distance between tunnels and dung, and in tunnel depth. Patterns of succession and diel activity demonstrated strong temporal dissociations among guilds. In one species, Onthophagus multicornis, we found a bimodal distribution of male horn sizes and a tunneling pattern consistent with alternative reproductive tactics.
\end{abstract}

Keywords Dung beetles $\cdot$ Kibale National Park $\cdot$ niche partitioning $\cdot$ Onthophagus multicornis $\cdot$ reproductive strategy

\footnotetext{
A. Chao $\cdot$ R. Simon-Freeman $\cdot$ G. Grether

Department of Ecology and Evolutionary Biology, University of California,

Los Angeles, CA 90095, USA
}

\author{
A. Chao $(\bowtie)$ \\ 5 Brady Place, Menlo Park, CA 94025, USA \\ e-mail: poodless88@gmail.com
}

Present Address:

A. Chao

Department of Microbiology, Perelman School of Medicine, University of Pennsylvania, Philadelphia, PA 19104, USA 
Mammalian dung is a high quality, but scattered and ephemeral, resource that supports many of the over 8,000 species of coprophagus dung beetles (Coleoptera: Scarabaeoidea; ScarabNet Global Taxon Database version 1.5). Within local species assemblages, dung beetles exhibit niche partitioning along several ecological axes (Hanski and Cambefort 1991a), including dung colonization times (Hanski 1980a), seasonality (Hanski 1980b; Jay-Robert et al. 2008), diel activity (KrellWesterwalbesloh et al. 2004), trophic preferences (Martin-Piera and Lobo 1996), as well as in foraging and nesting strategies (Cambefort and Hanski 1991). Speciesspecific dung preferences have been documented based on dung odour (Dormont et al. 2010), dung type (within and among trophic levels; Lumaret and Iborra 1996; Finn and Giller 2002), age (Doube 1987), and water content (Sowig and Wassmer 1994). Niche partitioning also occurs at the scale of individual dung pads (Halffter and Matthews 1966; Holter 1982; Edwards and Aschenborn 1987).

Dung beetles can be classified into guilds or functional groups (FG) based on modes of foraging and dung burial (Doube 1990). Telecoprids (referred to here as 'rollers') roll away small portions of dung before burying and laying eggs in them, whereas endocoprids lay eggs directly within the dung, and paracoprids (referred to here as 'tunnelers') construct nests under the dung pad prior to laying eggs. Kleptocoprids lay eggs in dung buried by other dung beetles. Functional categorization can be further broken down by body size, which is a strong predictor of competitiveness (Moczek and Emlen 2000; Safryn and Scott 2000). This system provides a framework for analyzing the structure of many dung beetle communities (for example, Giller and Doube 1994; Krell and Krell-Westerwalbesloh 2003).

The local partitioning of resources below individual dung pads is less well known (but see Holter 1982; Cambefort and Hanski 1991), perhaps due to the inherent difficulties in observing underground activity. Tunnelers construct nests at different positions below and away from the dung pad, and there are clear differences in nest architecture between species (Halffter and Edmonds 1982). Underground stratification of nest sites may serve to optimize each inhabitant's reproductive efforts and may also help to mediate coexistence of species with similar life histories.

Underground distribution may also reflect differences in reproductive strategies within species. Intense intra-sexual competition is thought to have resulted in the evolution of alternative mating tactics in male dung beetles (Emlen et al. 2005), where small males (minors) may gain little from direct competition with large males (majors) and instead adopt a 'sneaker' strategy of opportunistic copulation (Eberhard 1982).

The aims of this study were to: (1) characterize the activity patterns and nesting behavior of an East African dung beetle assemblage; (2) document patterns of spatial and temporal partitioning above and below the dung pad; and (3) examine the relationship of these phenotypes with corresponding inter- and intraspecific variation in morphology.

\section{Methods}

Study Site This study was conducted in and around the Makerere University Biological Field Station (MUBFS) located within Kibale National Park, western Uganda ( $766 \mathrm{~km}^{2} ; 0^{\circ} 13^{\prime}$ to $0^{\circ} 41^{\prime} \mathrm{N}$ and $0^{\circ} 19^{\prime}$ to $\left.30^{\circ} 32^{\prime} \mathrm{E}\right)$. The Kibale forest is a medium-altitude moist forest that is a mosaic of tall evergreens, swamp, thickets and 
grasslands. Kibale averages 1,670 mm of rainfall per year with two rainy seasons, in March to May and September to November (Shepherd and Chapman 1998). This study was conducted from the $6^{\text {th }}$ to the $23^{\text {rd }}$ of February of 2009 , which coincides with the end of the dry season.

Despite its fragmented landscape, the mammalian fauna of Kibale is still one of the most diverse and relatively intact communities in the tropics. 23 mammalian families are represented in Kibale. Its 11 species of primates make up one of the highest populations and biomass densities of primates anywhere in the world (Oates et al. 1990). The accompanying range and abundance of mammalian dung is likely to serve to enhance the diversity of the dependent dung beetle fauna.

Classification of Beetles and Species Identification When characterizing dung beetle communities, it is useful to group species into guilds based on modes of foraging and dung burial. We used a modified version of Doube's (1990) system of classifying species into functional groups (FG) according to mode of dung acquisition (roller or tunneler) and size (large or small) (Table 1). According to Doube's classification, FG III include smaller tunnelers, while FG IV include larger tunnelers. We were not able to classify the tunnelers Heliocopris haroldi and Onitis viridulus in this way due to insufficient behavioral observations.

Digital photographs were taken of specimens captured in the vicinity of MUBFS using a $100 \mathrm{~mm}$ macro lens and sent to Philippe Moretto for species

Table 1 Summary of identified species sorted by guild and functional group

\begin{tabular}{|c|c|c|c|c|c|}
\hline Guild & FG & Species & Counts & Size $(\mathrm{mm})$ & Dung type \\
\hline \multirow[t]{3}{*}{ Rollers } & I & Garreta crenulatus Kolbe & 60 & $11.41(58)$ & $\mathrm{E} \& \mathrm{P}$ \\
\hline & $\mathrm{I}$ & Anachalcos cupreus Fabricius & 5 & ca. 13 & $\mathrm{E} \& \mathrm{P}$ \\
\hline & II & Sisyphus sp. & 28 & ca. 5 & $\mathrm{P}$ \\
\hline \multirow[t]{8}{*}{ Tunnelers } & III & $\begin{array}{l}\text { Onthophagus (Proagoderus) } \\
\text { multicornis d'Orbigny }\end{array}$ & 213 & $7.32(154)$ & $\mathrm{E} \& \mathrm{P}$ \\
\hline & III & Onthophagus mixtidorsis d'Orbigny & 88 & ca. 7 & $\mathrm{E} \& \mathrm{P}$ \\
\hline & III & Onthophagus fuscidorsis d'Orbigny & 25 & ca. 5 & $E \& P$ \\
\hline & IV & Catharsius ninus Gillet & 69 & $8.86(55)$ & $\mathrm{P}$ \\
\hline & IV & $\begin{array}{l}\text { Onthophagus (Diastellopalpus) } \\
\text { semirubidus d'Orbigny }\end{array}$ & 61 & $11.50(40)$ & $\mathrm{E} \& \mathrm{P}$ \\
\hline & IV & $\begin{array}{l}\text { Onthophagus (Diastellopalpus) } \\
\text { gilleti d'Orbigny }{ }^{a}\end{array}$ & 11 & $11.57(3)$ & $\mathrm{E} \& \mathrm{P}$ \\
\hline & - & Heliocopris haroldi Kolbe & 4 & ca. 25 & $\mathrm{E}$ \\
\hline & - & Onitis viridulus Boheman & 3 & ca. 11 & $\mathrm{E}$ \\
\hline
\end{tabular}

Species names follow ScarabNet Global Taxon Database version 1.5 (http://216.73.243.70/scarabnet/ results.htm). Species in bold are discussed in the text. Counts are the total observed and recorded individuals for all parts of this study. Size: mean elytra width with number of individuals measured in parentheses. Dung type: $\mathrm{E}=$ sampled in elephant dung, $\mathrm{P}=$ sampled in primate dung. FG: $\mathrm{I}=$ large telecoprids, II=Small telecoprids, III=small, early-appearing paracoprids, IV=larger, late-appearing paracoprids

${ }^{a}$ first record in Uganda 
identification. Identification of some beetles beyond the generic level was not possible, including a few Sisyphus species (Table 1). Elytra width and horn length were measured on dung beetles collected from dung pads from both human and naturally occurring primate and elephant dung. One person (AC) performed all measurements with dial calipers to varying levels of precision, depending on species, morph and body part (Table 1).

In Situ Observations Diurnal species-specific arrival times and above-ground behaviors were recorded at 12 sites. All sites were located in areas of recent primate sightings ( $<2$ days) near MUBFS. Roughly $60 \mathrm{ml}$ of fresh human feces $(<3$ days old) was placed in the center of a circular clearing (approximate radius $30 \mathrm{~cm}$ ) of shaded forest floor at 09:30. Behavioral observations were either carried out immediately after placement of feces at 6 sites or starting 1-hour post-placement at the other 6 sites. Each observation session lasted 2 continuous hours (i.e., 09:30-11:30 or 10:30-12:30).

The 12 sites used for above-ground observations and 3 additional sites were randomly assigned to be excavated at 5, 24, or $48 \mathrm{~h}$ after placement of dung. Five excavations were completed at each time (15 excavations total). Excavations involved first recording the presence of beetles above ground, then systematically unearthing the surrounding soil, beginning $30 \mathrm{~cm}$ away from the approximate center of the dung pad, at a depth of no less than $10 \mathrm{~cm}$. Excavations proceeded inwards until the entire pad had been removed and sifted through by hand. Data on morphospecies and corresponding depth and distance from center of dung pad were recorded for each individual beetle.

Experimental Observations To investigate diel separation in Kibale's dung beetle community, above-ground activity was observed around the clock in an observation enclosure for seven commonly occurring species: Onthophagus multicornis $(N=106)$, O. mixtidorsis d'Orbigny $(N=32)$, O. semirubidus $(N=15)$, O. gilleti d'Orbigny $(N=4)$, Garreta crenulatus $(N=35)$, Catharsius ninus $(N=21)$, Anachalcos cupreus $(N=5)$. All beetles were collected from naturally occurring primate and elephant dung pads and were allowed to intermingle in a plastic container $(40 \times 30 \times 20 \mathrm{~cm})$ filled with approximately $4 \mathrm{~cm}$ of soil and covered with breathable plastic netting. Beetles were thus allowed to move freely above and below ground but with restricted flight. Approximately $90 \mathrm{ml}$ of non-human primate dung was provided daily at around 9 am and the number of active individuals and species above ground was counted via hourly scan sampling. An individual was regarded as active if it was above ground and moving. Three sets of 24-hour activity observations were conducted, with hourly sampling. Samples were not necessarily collected in consecutive hours, but rather, completed over the course of 7 days.

Statistical Methods Hierarchical ANOVA, with species nested within guild, was used to test for heterogeneity in arrival times among guilds and among species within guilds; arrival time was square-root transformed for this analysis to normalize the residuals. Likewise, hierarchical ANOVA, with species nested within tunneler functional group, was used to test for heterogeneity among groups in tunnel depth and 
distance of tunnels from the dung pad. Chi-square tests of independence were used to test for differences among guilds in the temporal and spatial distributions of beetles at dung pads.

We used a segmented regression model (Eberhard and Gutiérrez 1991) to describe male horn allometry in Onthophagus multicornis using R 2.8.1 (The R Foundation for Statistical Computing http://www.R-project.org), in which X and Y are measurements of elytra width and horn length, respectively. We searched for a switch point by adjusting the $\Psi$ parameter of the model (R function "segmented()") incrementally, and selecting the best model based on AIC. We then compared the best fitting segmented regression model with a linear and logarithmic model, again using AIC as the criterion for selecting the best model (Okada et al. 2008). We used nonparametric Kruskal-Wallis, Wilcoxon, and Levene's tests when the data appeared to violate parametric assumptions of normality or homoscedasticity.

\section{Results}

Local Fauna A total of 567 individuals of 11 species, belonging to 7 genera, were collected and identified (Table 1). Paracoprids (tunnelers) represented the majority of the Kibale dung beetle community (6 of 9 species that could be classified). No observed species exhibited the endocoprid strategy of nesting in the dung itself. The smaller species within Onthophagus and Sisyphus were the most abundant members of the tunneling and ball-rolling guilds, respectively.

Succession Roller species arrived sooner after dung placement than tunneler species (Table 2; guild $F_{1,117}=6.64, P=0.01$; species nested within guild $F_{4,117}=1.15$, $P=0.34 ; R^{2}=0.10$; excluding the two species with no replication). Rollers and tunnelers also differed in their temporal distribution below the dung pad over the 5-48 h excavation period (Chi-squared test, $\left.X^{2}=7.48, \mathrm{df}=2, P=0.024\right)$. Only 3 of 55 arriving rollers were still present at the dung pad by $5 \mathrm{~h}$ after dung placement and none were present at the 24 and 48-hour marks (Table 3).

Table 2 Arrival times

\begin{tabular}{lllllll}
\hline & Guild & FG & Counts & Range & Mean & S.E. \\
\hline Anachalcos cupreus & R & I & 1 & n/a & 15 & n/a \\
Garreta crenulatus & R & I & 11 & $5-120$ & 43 & 12 \\
Sisyphus sp. & R & II & 26 & $10-160$ & 58 & 7 \\
Onthophagus fuscidorsis & T & III & 16 & $22-165$ & 67 & 10 \\
Onthophagus multicornis & T & III & 17 & $11-163$ & 70 & 10 \\
Onthophagus mixtidorsis & T & III & 47 & $5-166$ & 86 & 7 \\
Onthophagus gilleti & T & IV & 1 & n/a & 23 & n/a \\
Onthophagus semirubidus & T & IV & 6 & $10-155$ & 75 & 22 \\
\hline
\end{tabular}

Arrival times (in minutes) of beetles arriving on the surface of the dung pad within the first $3 \mathrm{~h}$ of dung placement. The two species with no replication were omitted from the statistical analysis. $\mathbf{T}=$ tunneler, $\mathbf{R}=$ roller 
Table 3 Summary of excavations by functional group

Number of individuals, sorted by $\mathrm{FG}$, present on or under dung pad at 5, 24 and $48 \mathrm{~h}$ post-placement of dung

\begin{tabular}{lccc}
\hline & $5 \mathrm{~h}$ & $24 \mathrm{~h}$ & $48 \mathrm{~h}$ \\
\hline Rollers (FG I \& II) & 3 & 0 & 0 \\
Large tunnelers (FG IV) & 0 & 54 & 32 \\
Small tunnelers (FG III) & 52 & 46 & 3 \\
\hline
\end{tabular}

The temporal distributions of beetles of FG III and FG IV below the dung pad differed significantly $\left(X^{2}=75.95, \mathrm{df}=2, P<0.001\right.$; Fig. 1$)$. Small tunnelers (FG III) were abundant below the dung pad at the $5 \mathrm{~h}$ and $24 \mathrm{~h}$ marks but virtually disappeared by $48 \mathrm{~h}$ post-placement (Table 3). In contrast, large tunnelers (FG IV) were not recorded until $24 \mathrm{~h}$ post-placement and were present at least until $48 \mathrm{~h}$ post-placement (Table 3).

In the observation enclosure, rollers (FG I) were most active above ground during daylight hours (Fig. 2), while the tunneler Catharsius ninus (FG IV) showed the mirror opposite pattern. Tunnelers (FG III and FG IV) showed sporadic activity, mostly under daylight. Most species of FG IV, except Catharsius ninus, tended to be crepuscular.

Spatial Separation Below Dung Pad Excavations in the vicinity of dung pads revealed significant heterogeneity among species in the lateral distance between tunnels and dung pads (one-way ANOVA, $F_{5,88}=5.12, P<0.001$, adj $R^{2}=0.18$ ) and in tunnel depth $\left(F_{5,88}=11.26, P<0.001\right.$, adj. $\left.R^{2}=0.35\right)$. The larger, later-appearing species in FG IV dug tunnels significantly farther from the dung pad and at greater depths than species in FG III (ANOVA with species nested within FG tunnel distance: FG term $F_{1,88}=16.43, P<0.001$, adj $R^{2}=0.18$; tunnel depth $\mathrm{FG}$ term $F_{1,88}=27.56$, $P<0.001$, adj $R^{2}=0.42$; Fig. $3 \mathrm{a}, \mathrm{b}$ ). Across species, mean body size (as measured by elytra width) correlated positively with mean distance between tunnel and dung pad

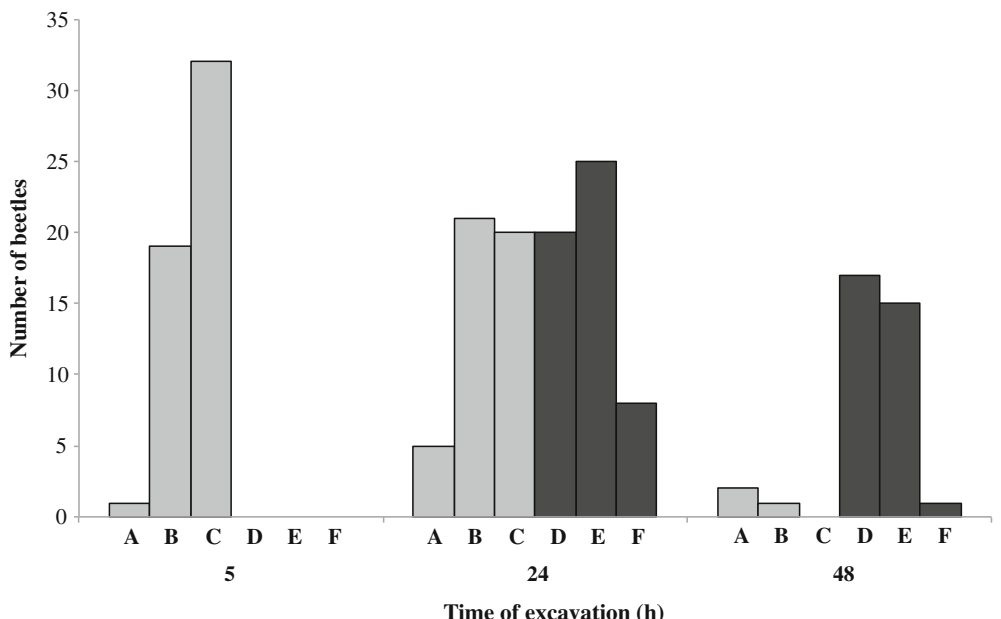

Fig. 1 Temporal distribution of tunnelers categorized by functional group. Light shading: FG III. Dark shading: FG IV. Species codes: a, Onthophagus fuscidorsis; b, O. mixtidorsis; c, O. multicornis; d, Catharsius ninus; e, O. semirubidus; f, O. gilleti 


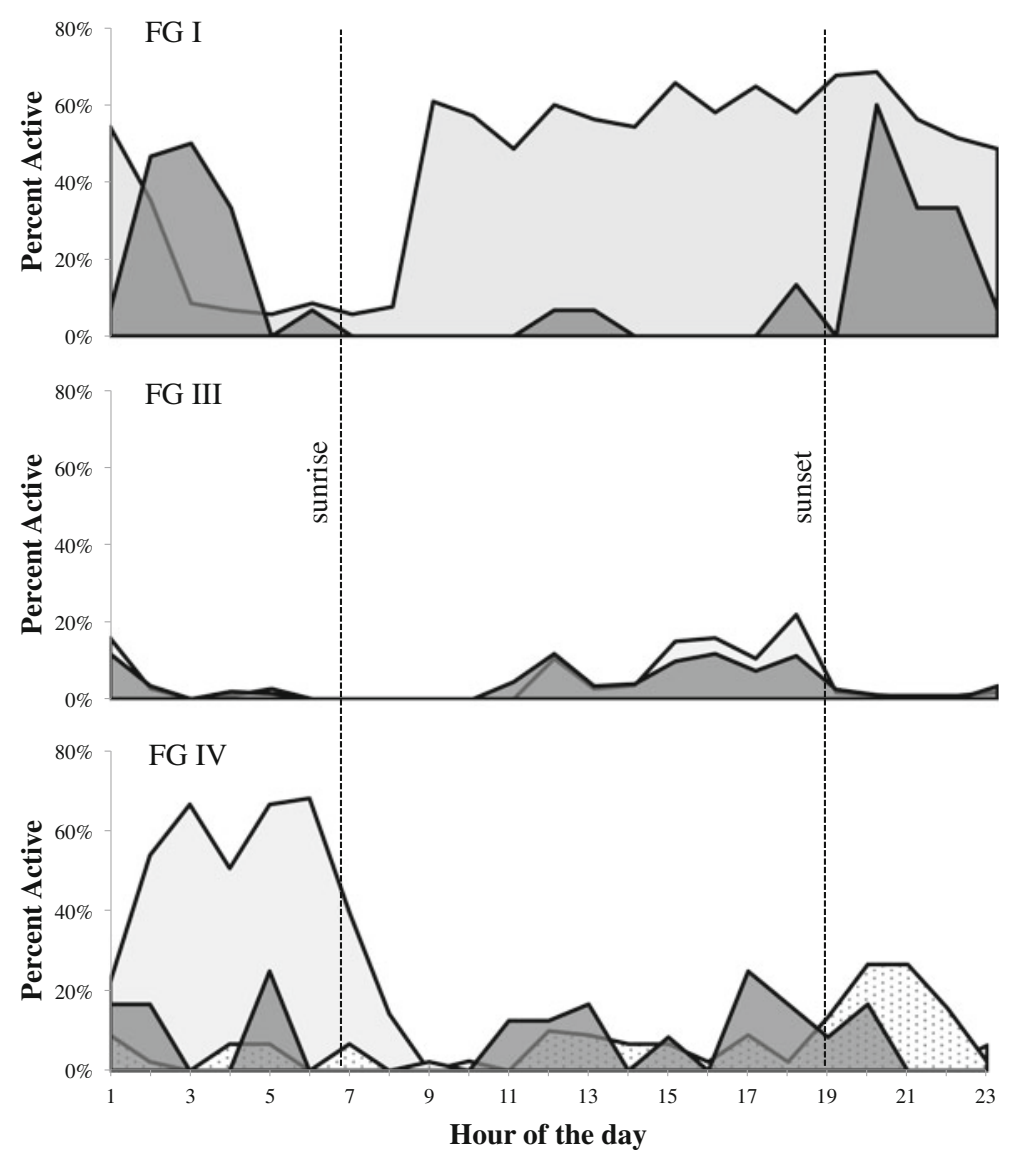

Fig. 2 Surface activity pattern of seven commonly occurring species, grouped by functional group. Percent Active: percent of individuals active out of total number within species. FG I: Garreta crenulatus $(N=35$, light grey), Anachalcos cupreus ( $N=5$, dark grey); FG III: Onthophagus multicornis $(N=38$, light grey), O mixtidorsis $(N=68$, dark grey); FG IV: Catharsius ninus $(N=21$, light grey), Onthophagus gilleti $(N=4$, dark grey), O. semirubidus $(N=15$, dotted $)$. Sunrise was at 06:50 and sunset was at 18:56, approximately

( $r=0.89, P=0.018, N=6)$ but not with mean tunnel depth $(r=0.52, P=0.29, N=6)$. Neither tunnel distance nor tunnel depth correlated significantly with body size within species (for all 12 correlations, $P>0.05$ ).

Alternative Reproductive Behavior of a Tunneler Onthophagus multicornis was the most rapid and common diurnal dung burrier. Horn lengths in male $O$. multicornis showed a continuous, bimodal distribution ranging from less than a $1 \mathrm{~mm}$ up to 8.56 $\mathrm{mm}$ in length (Fig. 4). Male elytra width also showed a faint bimodality (Fig. 5). Larger males possessed horns protruding from the head, whereas smaller males had shorter or vestiges of horns. The relationship between horn length and body size (Fig. 6) was best fit by a segmented linear regression with a switch point at an elytra width of $7.74 \mathrm{~mm}$ (AIC scores: segmented 172.93; logarithmic 178.56; linear 181.04). We used this switchpoint to separate males into either "majors" (with elytra width greater than $7.74 \mathrm{~mm}$ ) and "minors" (with elytra width less than $7.74 \mathrm{~mm}$ ), and 

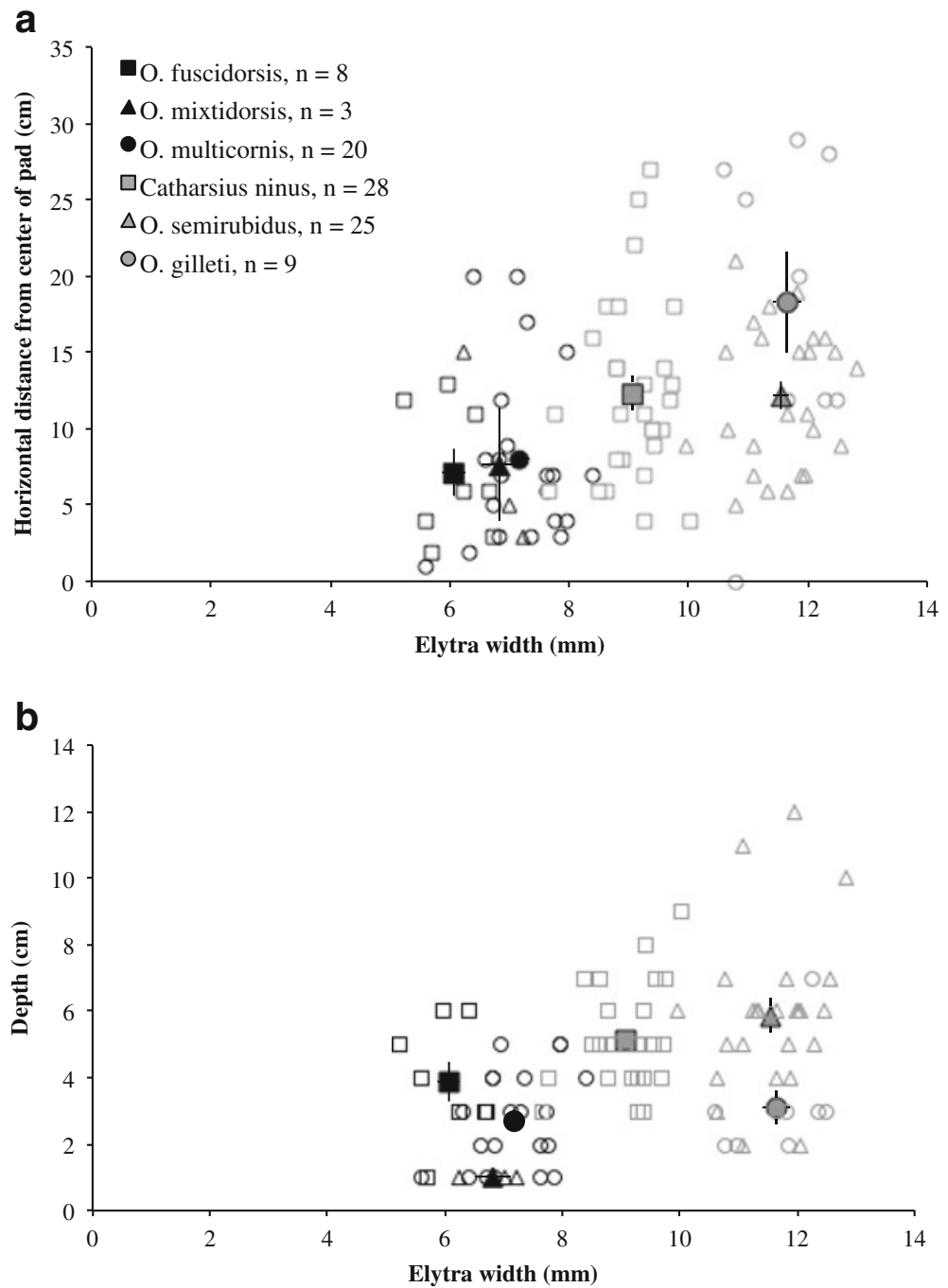

Fig. 3 Spatial distribution of individuals (open points, $N=93$ ) and species (filled points, mean, SE) within the tunneling community in terms of horizontal distance away from center of dung pad (a) and depth (b). Black filled/outlined points: FG III; Grey filled/outlined points: FG IV

determined whether the difference in male morph coincided with a change in behavior as approximated by our data on tunneling patterns.

We excavated 52 individuals of $O$. multicornis from the dung pads, all of which were found during the 5 and 24-hour mark (none were found at the 48-hour mark). There was a significant temporal difference between female, majors and minors (Kruskal-Wallis rank sum: $H=7.188 \mathrm{df}=2, P=0.027$ ). Specifically, majors arrived later than both minors (Wilcoxon test: $N=33, W=153, P=0.026$ ) and females (Wilcoxon test: $N=28, W=41.5, P=0.013$ ) . The number of of females and minors decreased, and the number of majors increased from the 5-hour mark (female: 14, minor: 16, major: 2) to the 24-hour mark (female: 5, minor 8, major: 7), and this shift in composition was statistically significant (Chi-squared test, $\chi^{2}=7.329, \mathrm{df}=2, P=0.026$ ). 


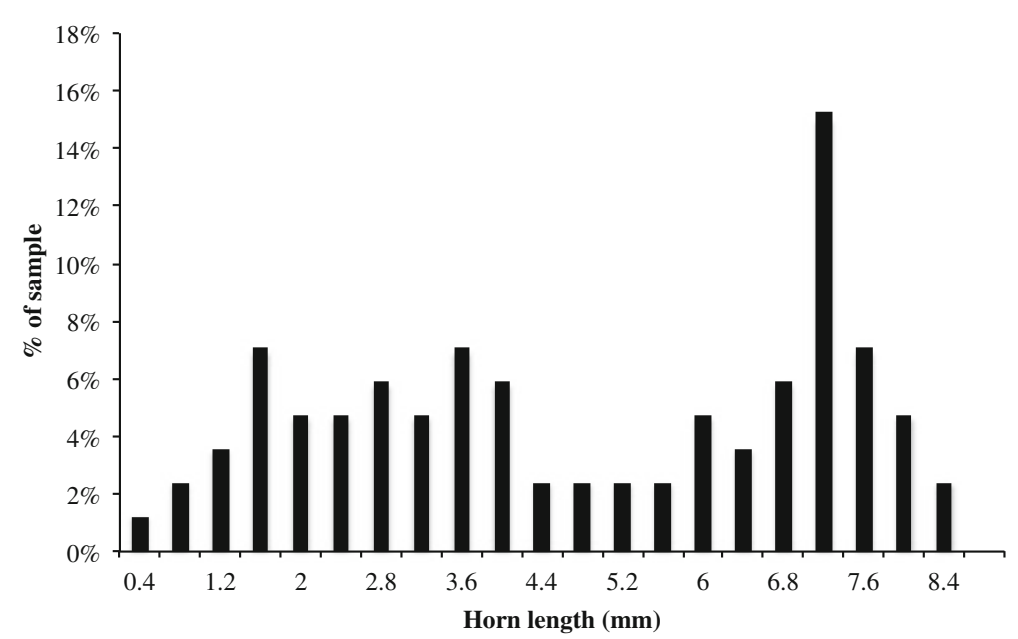

Fig. 4 Distribution of horn length of male $O$. multicornis is continuous and bimodal. Horn lengths ranged from $0.64 \mathrm{~mm}$ to $8.53 \mathrm{~mm}$, with a mean of $4.97 \mathrm{~mm}$ and median of $4.83 \mathrm{~mm}(N=85)$. For analysis, the median horn length was used as an estimation of the cut-off point between male morphs: minors $(N=43$, $<4.83 \mathrm{~mm})$; majors $(N=42,>4.83 \mathrm{~mm})$

Furthermore, horn length and elytra width increased with time from the 5-hour mark to the 24-hour mark (Wilcoxon test: $N=33, W=79, P=0.043 ; N=33, W=73$, $P=0.026$, respectively).

We observed no significant overall spatial separation between the three groups (females, minors, and majors), in horizontal distance from the dung pad (Kruskal-Wallis test: $H=3.913, \mathrm{df}=2, P=0.141$ ), nor in vertical distance below the dung pad $(H=0.108, \mathrm{df}=2, P=0.948)$. No significant difference in horizontal distance from the dung pad (distance) and vertial distance below the dung pad (depth)

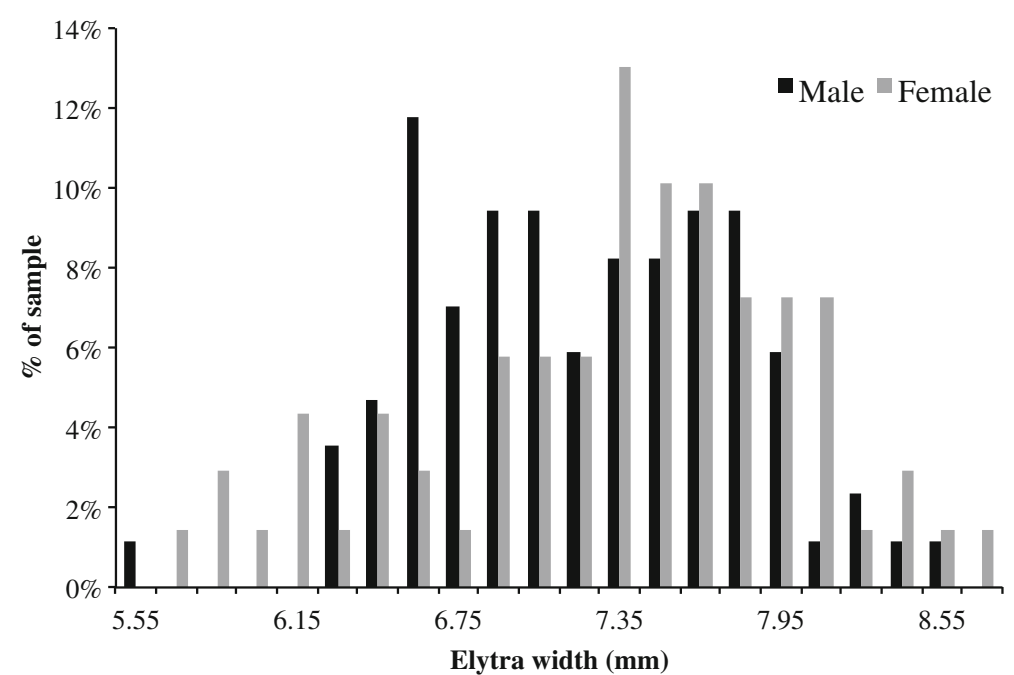

Fig. 5 Male $O$. multicornis elytra width show a slight bimodel distibution $(N=85)$, in contrast to those of female $O$. multicornis $(N=69)$ 


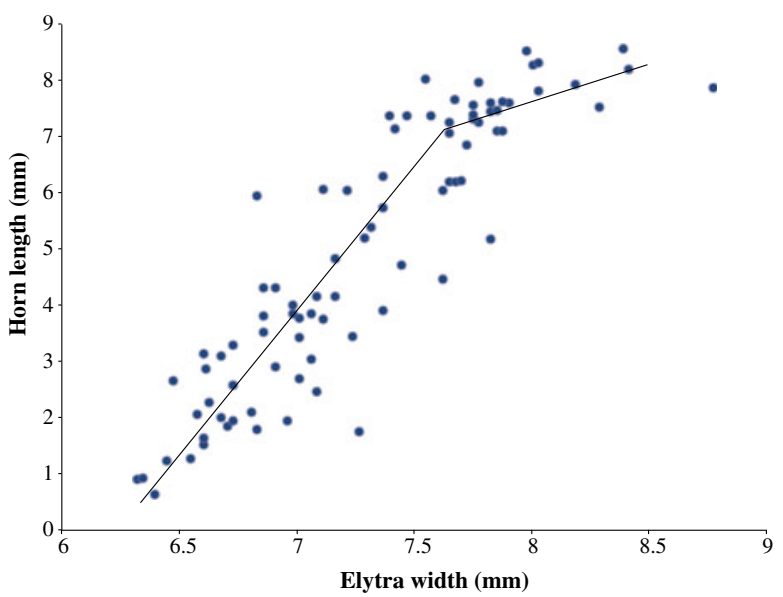

Fig. 6 Male horn allometry of 85 male $O$. multicornis analyzed via a segmented regression model (as in Eberhard and Gutiérrez 1991). A switchpoint occurs at elytra width of $7.75 \mathrm{~mm}$

was observed between females and males (Wilcoxon test: $N=52$; distance: $W=216.5$, $P=0.065$; depth: $W=297, P=0.756$ ) and between majors and minors (Wilcoxon test: $N=33$; distance: $W=92, P=0.529$; depth: $W=109, P=0.9835)$. No significant overall variance in horizontal or vertical tunnel location was found (Levene test: $F=3.537$, $\mathrm{df}=2, P=0.057 ; F=1.302, \mathrm{df}=2, P=0.281$, respectively). Nevertheless, males occupied a wider variation of horizontal tunnel positions than females did (Levene test: $F=7.053, \mathrm{df}=1, P=0.011$; Fig. 7).

\section{Discussion}

Local Fauna All data were collected during the end of the long dry season, which most likely explains the lower species count compared to a previous study that recorded 14 species in the same selectively felled forest (Nummelin and Hanski

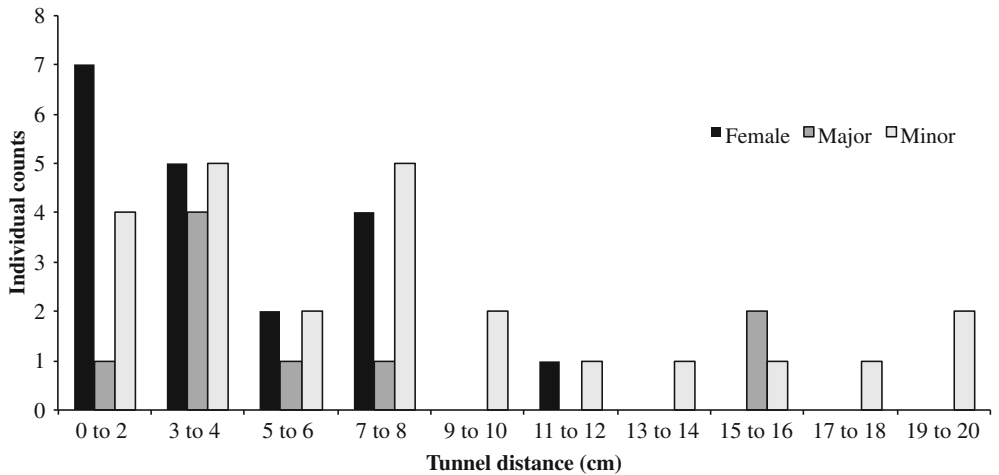

Fig. 7 Tunnel distances away from center of dung pad of different $O$. multicornis morphs and sex. Female $N=19$, majors $N=16$, minors $N=17$. Distance away from dung: females, $\mu=4.3 \mathrm{~cm} \mathrm{SE}=0.6$; majors, $\mu=6.3$ $\mathrm{cm}$ S.E. $=1.3$, minors, $\mu=8.4 \mathrm{~cm} \mathrm{S.E.}=1.5$ 
1989). As observed in previous studies in the forests of Uganda (Nyeko 2009), smallbodied, earlier appearing species (FG III) were the most abundant, constituting 326 of 567 documented individuals.

Spatial Separation Most studies of spatial partitioning in dung beetles have been concerned with large-scale (i.e., across regional habitats, across dung-pads) distributions of coexisting species (Hanski 1980a; Cambefort and Hanski 1991). Intraspecific aggregation across dung pads is well documented and has been argued to foster coexistence of competing species (Holter 1982; Giller and Doube 1994; Hutton and Giller 2004). We studied spatial partitioning of beetles within dung-pads and found that intraspecific aggregation occurs at this scale as well. Interspecific variation in body size appears to play a key role in determining the spatial distribution of tunnelers below the dung pad. Specifically, late-appearing species nested farther and deeper than smaller, early-appearing species.

Species-specific patterns in tunnel and nest structure (Halffter and Matthews 1966; Edwards and Aschenborn 1987), and in nesting location relative to the dung pad (Holter 1982), may reflect past interspecific competition, or interspecific competition during seasons of higher beetle abundance and diversity, or reproductive interference (Holter 1982; Gröning and Hochkirch 2008). Larval development time is long and resource intensive in rollers and tunnelers (Holter 1975) and is hampered by competitive interactions due to high beetle density (Holter 1979). Spatial separation of oviposition sites may reduce both direct (interference) and indirect (exploitative) competition and may also help protect broods from predators, parasites, and pathogenic fungi (Hanski and Cambefort 1991b). These explanations for spatial differentiation do not necessarily predict a size-dependent pattern of nesting locations between species and guilds, however.

We found that larger species of tunnelers nested farther from the dung pad than smaller species. We can think of three non-mutually exclusive explanations for this trend. First, physiological constraints imposed by body size, combined with a trade-off between the costs of digging tunnels and transporting dung versus the benefits of ovipositing farther from the dung pad, may result in a greater optimal distance for larger species. Large species are able to maintain higher internal body temperatures and consequently can move faster than small species (Chown and Klok 2011). For small species, the benefits of ovipositing farther from the dung pad (e.g., lower larval competition) may not be sufficient to offset the additional energetic costs and risks associated with constructing more extensive tunnels and transporting dung above ground (e.g., predation, parasitism). Second, larval competition increases with larval density, and may affect the organization of oviposition sites. The rate of oviposition decreases with increased adult density (Holter 1979) and larval mortality rate increases with number of eggs in a dung pad (Hirschberger 1998). Larvae of large species may be more vulnerable to competition because they are slower to develop, resulting in a greater optimal distance from the dung pad for larger species. Finally, the correlation between size and distance from the dung pad may arise simply because late-arriving beetles need to nest farther away to avoid competition with early-arriving beetles. Further research will be required to determine which factor, or combination of factors, best accounts for the observed spatial patterns. 
Temporal Separation Temporal resource partitioning was observed between diurnal rollers (telecoprids) and tunnelers (paracoprids). Rollers were the first to arrive $(<3 \mathrm{~h})$ and tunnelers dominated the dung pad community soon after $(>5 \mathrm{~h})$. Another distinction arose later on; smaller tunnelers arrived and left earlier than their larger counterparts (Table 3 ). This pattern is consistent with that found in a local assemblage in southern Africa, where Doube (1990) observed that smaller tunnelers (FG III) interact approximately 6-24 $\mathrm{h}$ with the dung pad prior to departing, while larger tunnelers (FG IV) can remain up to 6 weeks.

At the proximate level, these temporal displacements may reflect guildspecific preference in dung freshness (as in Yasuda 1987; Doube et al. 1988). The ultimate reason may be that rollers need to arrive early to compete effectively with tunnelers. The rate of dung accumulation for rollers is severely limited by the time it takes to cut, roll and store a ball safely away from the source. This highly energetic form of foraging may require high body temperatures. The rate of ball rolling is dependent on body temperature (Bartholomew and Heinrich 1978), which may be prohibitively low at night. Indeed rollers were most active during daylight hours (Fig. 2). Nocturnal tunnelers, such as Catharsius ninus (Fig. 2), may avoid competition with the competitively superior diurnal ball rollers by exploiting the temporal refuges left by such constraints (Walter 1985; Krell-Westerwalbesloh et al. 2004).

Tunnelers were slow to arrive, but what temporal advantage they lose to rollers, they may regain through a larger inherent capacity to horde dung (Halffter and Edmonds 1982). Likewise, larger tunnelers appeared under the dung pad later than smaller tunnelers, but are capable of gathering more dung (up to 1000x the mass of the beetle; Doube 1990). Perhaps small species exemplify a scramble competition strategy while large species exemplify a contest competition strategy. For larger species, being competitive at the dung pad necessitates large body size (Moczek and Emlen 2000; Safryn and Scott 2000), which in turn demands greater accumulation of dung per brood. Small species demand less dung per brood and can effectively outcompete larger species by sheer numbers. When this is not the case, as in this study, smaller species require effective strategies to avoid direct competition, such as arriving before larger species monopolize the dung pad.

Alternative Mating Strategy in Onthophagus multicornis Dimorphisms in dung beetle horn lengths, particularly in the genus Onthophagus, are frequently associated with alternative reproductive behaviors. In some well-studied species (e.g., O. acuminatus, $O$. taurus, O. binodis), larger horned males, termed majors, defend tunnels against other males and in some cases help residing females with brood mass construction. In contrast, smaller horned males, termed minors, avoid direct confrontation with majors and attempt sneak copulations (Cook 1990; Emlen 1997; Hunt and Simmons 2000). Our morphological measurements and field observations are consistent with a similar pattern of alternative reproductive tactics in $O$. multicornis. Minors arrived earlier than majors, which may enable them to copulate with undefended females. Minors also occupied a wider range of lateral tunnel positions than both females and majors (Fig. 7). While these observations support the hypothesis of alternative male reproductive tactics in male $O$. multicornis, additional research is clearly needed to fully characterize the alternative tactics of this species. 
Horn dimorphisms in Onthophagus are commonly underlain by a sigmoidal relationship between horn size and body size (Emlen 1994, 2008; Hunt and Simmons 1997; Moczek and Emlen 1999; Rowland and Emlen 2009). Abrupt changes in horn length have been shown to correspond with the switch from sneaking to fighting tactics (Hunt and Simmons 2000), and may be indicative of a developmental reprogramming event (Emlen and Nijhout 2000, 2001). We did not find a sigmoidal relationship in O. multicornis. Instead, horn length increased linearly with body size up to a point, above which the slope of the allometry decreased noticeably. This scaling relationship was best fit by a segmented regression model with one switchpoint (Fig. 6). Whether this relatively subtle shift in horn development corresponds with a switch in behavioral tactics remains to be determined.

Synopsis We found evidence for fine-scale niche partitioning within and between guilds in the dung beetle assemblage of Kibale forest, Uganda. We also uncovered what appears to be an alternative male reproductive strategy in one tunneling species (O. multicornis). We hope our findings stimulate further research on the surprisingly understudied dung beetles of East Africa.

Acknowledgements We thank MUBFS Director John Kasenene of Makerere University for permission to carry out the project and Colin Chapman, Dennis Twinomugisha, and Patrick Omeja for helping facilitate our visit. Frank Krell and two anonymous reviewers provided invaluable comments on previous versions of the manuscript. Special thanks to Philippe Moretto for identifying the beetles, and Neil Losin for help on the statistical methods. Funding for this project was provided by the Department of Ecology and Evolutionary Biology and the Office of Instructional Development at UCLA.

\section{References}

Bartholomew GA, Heinrich B (1978) Endothermy in African dung beetles during flight, ball making, and ball rolling. J Exp Biol 73:65-83

Cambefort Y, Hanski I (1991) Dung beetle population biology. In: Hanski I, Cambefort Y (eds) Dung beetle ecology. Princeton University Press, Princeton, pp 36-50

Chown SL, Klok JC (2011) The ecological implications of physiological diversity in dung beetles. In: Leigh LW, Ridsdill-Smith JT (eds) Ecology and Evolution of Dung Beetles. Wiley-Blackwell, pp. 200-219

Cook DF (1990) Differences in courtship, mating and postcopulatory behavior between male morphs of the dung beetle Onthophagus binodis Thunberg (Coleoptera: Scarabaeidae). Anim Behav 40:428-436

Dormont L, Jay-Robert P, Bessiere JM, Rapior S, Lumaret JP (2010) Innate olfactory preferences in dung beetles. J Exp Biol 213:3177-3186

Doube BM (1987) Spatial and temporal organization in communities associated with dung pads and caracasses. In: Gee JH, Giller PS (eds) Organization of communities past and present. Blackwell Scientific Pulblications, Oxford, pp 255-280

Doube BM (1990) A functional classification for analysis of structure of dung beetle assemblages. Ecol Entomol 15:371-383

Doube BM, Giller PS, Moola F (1988) Dung burial strategies in some south-african coprine and onitine dung beetles (Scarabaeidae, Scarabaeinae). Ecol Entomol 13:251-261

Eberhard WG (1982) Beetle horn dimorphism: making the best of a bad lot. Am Nat 119:420-426

Eberhard WG, Gutiérrez EE (1991) Male dimorphisms in beetles and earwigs and the question of developmental constraints. Evolution 45:18-28

Edwards PG, Aschenborn HH (1987) Patterns of nesting and dung burial in Onitis dung beetles implications for pasture productivity and fly control. J Appl Entomol 24:837-852 
Emlen DJ (1994) Environmental control of horn length dimorphism in the beetle Onthophagus acuminatus (Coleoptera: Scarabaeidae). Proc R Soc Lond B 256:131-136

Emlen DJ (1997) Alternative reproductive tactics and male dimorphism in the horned beetle Onthophagus acuminatus (Coleoptera: Scarabaeidae). Behav Ecol Sociobiol 41:335-341

Emlen DJ (2008) The roles of genes and the environment in the expression and evolution of alternative tactics. In: Oliveira RF, Taborsky M, Brockmann HJ (Eds) Alternative Reproductive Tactics: An Integrative Approach. Cambridge University Press, pp. 85-109

Emlen DJ, Marangelo J, Ball B, Cunningham CW (2005) Diversity in the weapons of sexual selection: horn evolution in the beetle genus onthophagus (Coleoptera: Scarabaeidae). Evolution 59:1060-1084

Emlen DJ, Nijhout HF (2000) The development and evolution of exaggerated morphologies in insects. Annu Rev Entomol 45:611-708

Emlen DJ, Nijhout HF (2001) Hormonal control of male horn length dimorphism in Onthophagus taurus (Coleoptera: Scarabaeidae): a second critical period of sensitivity to juvenile hormone. J Insect Physiol 47:1045-1054

Finn JA, Giller PS (2002) Experimental investigations of colonisation by north temperate dung beetles of different types of domestic herbivore dung. Appl Soil Ecol 20:1-13

Giller PS, Doube BM (1994) Spatial and temporal co-occurrence of competitors in south african dung beetle communities. J Anim Ecol 63:629-643

Gröning J, Hochkirch A (2008) Reproductive interference between animal species. Q Rev Biol 83:257-282

Halffter G, Matthews EG (1966) The natural history of dung beetles of the subfamily Scarabaeinae (Coleoptera: Scarabaeidae). Folia Entomol Mex 12-14:1-312

Halffter G, Edmonds WD (1982) The nesting behaviour of dung beetles (Scarabaeinae): an ecological and evolutive approach. Inst Ecología Méx 10:1-176

Hanski I (1980a) Patterns of beetle succession in droppings. Ann Zool Fenn 17:17-25

Hanski I (1980b) Spatial variation in the timing of seasonal occurrence in coprophagous beetles. Oikos 34:311-321

Hanski I, Cambefort Y (1991a) Resource partitioning. In: Hanski I, Cambefort Y (eds) Dung beetle ecology. Princeton University Press, Princeton, pp 330-349

Hanski I, Cambefort Y (1991b) Competition in dung beetles. In: Hanski I, Cambefort Y (eds) Dung beetle ecology. Princeton University Press, Princeton, pp 305-329

Hirschberger P (1998) Spatial distribution, resource utilization and intraspecific competition in the dung beetle Aphodius ater. Oecologia 116:136-142

Holter P (1975) Energy budget of a natural-population of aphodius-rufipes larvae (Scarabaeidae). Oikos 26:177-186

Holter P (1979) Abundance and reproductive strategy of the dung beetle aphodius-rufipes (L) (Scarabaeidae). Ecol Entomol 4:317-326

Holter P (1982) Resource utilisation and local coexistence in a guild of Scarabaeid dung beetles (Aphodius sp.). Oikos 39:213-227

Hunt J, Simmons LW (1997) Patterns of fluctuating asymmetry in beetle horns: an experimental examination of the honest hypothesis. Behav Ecol Sociobiol 41:109-114

Hunt J, Simmons LW (2000) Maternal and paternal effects on offspring phenotype in the dung beetle Onthophagus taurus. Evolution 54:936-941

Hutton SA, Giller PS (2004) Intra- and interspecific aggregation of north temperate dung beetles on standardised and natural dung pads: the influence of spatial scale. Ecol Entomol 29:594-605

Jay-Robert P, Errouissi F, Lumaret JP (2008) Temporal coexistence of dung-dweller and soil-digger dung beetles (Coleoptera, Scarabaeoidea) in contrasting Mediterranean habitats. B Entomol Res 98:303-316

Krell F-T, Krell-Westerwalbesloh S (2003) Spatial separation of afrotropical dung beetle guilds: a trade-off between competitive superiority and energetic constraints (Coleoptera: Scarabaeidae). Ecography 26:210-222

Krell-Westerwalbesloh S, Krell F-T, Linsenmair KE (2004) Diel separation of Afrotropical dung beetle guilds - avoiding competition and neglecting resources (Coleoptera: Scarabaeoidea). J Nat Hist $38: 2225-2249$

Lumaret JP, Iborra O (1996) Separation of trophic niches by dung beetles (Coleoptera, Scarabaeoidea) in overlapping habitats. Pedobiologia 40:392-404

Martin-Piera F, Lobo JM (1996) A comparative discussion of the trophic preferences in dung beetle communities. Misc Zool 19.1:13-31

Moczek AP, Emlen DJ (1999) Proximate determination of male horn dimorphism in the beetle Onthophagus taurus (Coleoptera: Scarabaeidae). J Evol Biol 12:27-37 
Moczek AP, Emlen DJ (2000) Male horn dimorphism in the scarab beetle Onthophagus taurus: do alternative reproductive tactics favor alternative phenotypes? Anim Behav 59:459-466

Nummelin M, Hanski I (1989) Dung beetles of the Kibale Forest, Uganda; comparison between virgin and managed forests. J Trop Ecol 5:349-352

Nyeko P (2009) Dung beetle assemblages and seasonality in primary forest and forest fragments on agricultural landscapes in Budongo, Uganda. Biotropica 4:476-484

Oates JF, White D, Gadsby EL and Besong PO (1990) Conservation of gorillas and other species. Appendix 1 to Cross River National Park (Okwangwo Division): Plan for developing the park and its support zone. Godalming, Surrey: World Wide Fund for Nature, United Kingdom

Okada Y, Fujisawa H, Kimura Y, Hasegawa E (2008) Morph-dependent form of asymmetry in mandibles of the stag beetle Prosopocoilus inclinatus (Coleoptera: Lucanidae). Ecol Entomol 33:684-689

Rowland JM, Emlen DJ (2009) Two thresholds, three male forms result in facultative male trimorphism in beetles. Science 323:773-776

Safryn SA, Scott MP (2000) Sizing up the competition: do burying beetles weigh or measure their opponents? J Insect Behav 13:291-297

Shepherd VE, Chapman CA (1998) Dung beetles as secondary seed dispersers: impact on seed predation and germination. J Trop Ecol 14:199-215

Sowig P, Wassmer T (1994) Resource partitioning in coprophagous beetles from sheep dung: phenology and microhabitat preferences. Zool Jb Syst 121:171-192

Walter P (1985) Diurnal and nocturnal flight activity of scarabaeine coprophages in tropical Africa. GeoEco-Trop 9:67-87

Yasuda H (1987) Differences in temporal utilization patterns of dung pats amongst three scarabaeid dung beetles. Jap J Appl Entomol Zool 28:167-177 